\title{
Plateau iris in Japanese patients with primary angle closure and primary angle closure glaucoma
}

This article was published in the following Dove Press journal:

Clinical Ophthalmology

29 June 2015

Number of times this article has been viewed

Mineo Ozaki ${ }^{2,3}$

Harumi Wakiyama ${ }^{1,4}$

Nobuchika Ogino ${ }^{1,5}$

'Mizoguchi Eye Clinic, Nagasaki, Japan;

${ }^{2}$ Ozaki Eye Clinic Miyazaki, Japan;

${ }^{3}$ Department of Ophthalmology,

Faculty of Medicine, University

of Miyazaki, Miyazaki, Japan; ${ }^{4}$ The

Japanese Red Cross Nagasaki

Genbaku Hospital, Nagasaki, Japan;

${ }^{5}$ Nishigaki Eye Clinic, Nagoya, Japan
Takanori Mizoguchi'
Correspondence: Takanori Mizoguchi Mizoguchi Eye Clinic, 6-13 Tawara-machi, Sasebo, Japan 857-0016

Tel +8I 95622568 I

Fax +8I 956256040

Email t-mizo@siren.ocn.ne.jp
Purpose: To determine the prevalence of plateau iris in Japanese patients with primary angle closure (PAC) and primary angle closure glaucoma (PACG) and analyze the biometric parameters in patients with plateau iris using ultrasound biomicroscopy (UBM).

Methods: In this cross-sectional observational study, subjects aged $>50$ years with PAC and PACG who had previously undergone a patent laser peripheral iridotomy underwent UBM in one eye. UBM images were qualitatively analyzed using standardized criteria. Plateau iris in a quadrant was defined by anteriorly directed ciliary body, absent ciliary sulcus, steep iris root from its point of insertion followed by a downward angulation, flat iris plane, and irido-angle contact. At least two quadrants had to fulfill these UBM criteria for an eye to be classified as having plateau iris. A-scan biometry was used to measure anterior segment parameters.

Results: Ninety-one subjects with PAC (58 subjects) or PACG (33 subjects) and 68 normal controls were recruited. The mean (standard deviation) ages of PAC and PACG patients and normal controls were 73.5 (6.2) and 72.6 (7.3), respectively. Based on UBM criteria, plateau iris was found in 16 eyes (17.6\%) of 91 eyes. In these 16 eyes, quadrant-wise analysis showed ten eyes $(62.5 \%)$ had plateau iris in two quadrants; four eyes $(25 \%)$ had plateau iris in three quadrants; and two eyes (12.5\%) had plateau iris in four quadrants. Anterior chamber depth, lens thickness, axial length, lens position, and relative lens position were not statistically significant between the group having plateau iris and that not having plateau iris, respectively.

Conclusion: Approximately 20\% of Japanese subjects with PAC and PACG with a patent laser peripheral iridotomy were found to have plateau iris on UBM. No morphological difference was noted in the anterior segment of the eye between those with or without plateau iris.

Keywords: ultrasound biomicroscopy, biometric parameters of anterior segment, plateau iris, angle closure

\section{Introduction}

Glaucoma is a major cause of visual loss worldwide, with primary angle closure glaucoma (PACG) representing an important cause of glaucoma blindness. ${ }^{1,2}$ Many patients with PACG are asymptomatic, and the progression to PACG with glaucomatous optic neuropathy may be rapid. The prevalence of PACG and primary angle closure (PAC) is significantly greater in Asian ethnic groups. ${ }^{1-5}$ Laser peripheral iridotomy (LPI) is the accepted first-line treatment in the management of eyes with PACG. However, there is a report of Asian eyes with PACG in which LPI alone was not able to prevent a clinically significant rise in intraocular pressure (IOP) from developing in most eyes during followup. ${ }^{6}$ This might be because LPI only relieves pupil block. Recent evidence has shown that non-pupil block mechanisms, such as plateau iris, may play a more important role in the PACG than previously thought. ${ }^{7,8}$ Irido-angle contact with plateau iris after LPI is thought to be one of the causes for progression of the angle closure disease. ${ }^{9-11}$ There are some reports that $30 \%$ of PAC suspects (PACS) from Singapore ${ }^{8}$ and $60 \%$ of PACS from the People's Republic of China were found to have plateau iris configuration. ${ }^{12}$ 
Plateau iris has been defined as an occludable angle on gonioscopy, with a flat iris plane and a relatively deeper central anterior chamber depth (ACD). The development of ultrasound biomicroscopy (UBM) has permitted highresolution images of the anterior segment and has allowed refinement of the definitions of the angle closure mechanisms. A recent study has shown that the anterior chamber associated with plateau iris syndrome is significantly shallower than in normal eyes and those with pupil block alone. ${ }^{13}$ The shallower anterior chamber in plateau iris may be explained by the fact that the anterior position of the ciliary processes produces an anterior position of lens. However, an anterior lens position (LP) is also the same condition that leads to pupillary block, and it is likely that these two conditions frequently coexist. ${ }^{13}$

The aim of this study was to determine the prevalence of plateau iris and to compare the anterior segment parameters in having plateau iris and not having plateau iris in Japanese patients with PAC and PACG, and to determine associations between these parameters and angle closure between the two groups.

\section{Methods}

This was a prospective study of Japanese subjects with PAC and PACG recruited from Mizoguchi Eye Clinic, Sasebo, Japan and Ozaki Eye Clinic, Miyazaki, Japan, who visited at these two clinics between October 2010 and September 2012. Written informed consent was obtained from all subjects and the study had the approval of the Institutional Review Board of the clinics and was performed in accordance with the tenets of the Declaration of Helsinki.

This cross-sectional study included subjects aged $>50$ years. PAC was defined as eyes in which the posterior trabecular meshwork was not seen for at least $270^{\circ}$ on gonioscopy in the primary position with peripheral anterior synechiae and/or raised IOP (defined as an IOP $\geq 21 \mathrm{mmHg}$ ) but without glaucomatous optic neuropathy or visual field loss. PACG was defined as eyes with PAC associated with glaucomatous optic neuropathy (defined as loss of neuroretinal rim, a vertical cup:disc ratio of 0.7 or an inter-eye asymmetry of 0.2 , and/or notching attributable to glaucoma). Patients diagnosed with secondary angle closure (such as neovascular glaucoma or uveitic glaucoma); patients who had corneal abnormalities that would affect imaging, prior history or evidence of acute PAC in the study eye, and previous laser iridoplasty or history of intraocular surgery; and patients on miotic therapy were excluded. All subjects with PAC and PACG had previously undergone LPI.
All subjects underwent a standardized eye examination that included visual acuity measurement, slit-lamp examination (model BQ 900; Haag-Streit, Bern, Switzerland), stereoscopic optic-disc examination with a 78-diopter lens (Volk Optical Inc, Mentor, OH, USA). IOP measurement by Goldmann applanation tonometry (Haar-Streit, Bern, Switzerland), and gonioscopy, were performed in the dark using a Goldmann two-mirror lens at magnification 16×. Indentation gonioscopy with a Sussman four-mirror lens was used to establish the presence or absence of peripheral anterior synechiae. A-scan biometry (model US-800; Nidek Co LTD, Nagoya, Japan) was used to measure axial length (AL), central ACD, and lens thickness (LT). These results were used to calculate $\mathrm{LP}$, defined as ACD $+1 / 2 \mathrm{LT}$, and relative LP (RLP), defined as LP/AL.

\section{UBM}

UBM(UD 6000; TOMEY Co., Nagoya, Japan) was performed in dark room conditions. Patients were examined in the supine position, and fixation and accommodation were held constant throughout. Radial scans were performed in the inferior, temporal, superior, and nasal quadrants for one eye. The probe was held perpendicular to the ocular surface, such that the scleral spur and ciliary body and angle were visualized.

UBM images were graded qualitatively in all four quadrants by a single glaucoma specialist (TM) without clinical information. Based on UBM images, plateau iris was defined in a quadrant if all the following criteria were fulfilled (Figure 1): $7^{7,8}$

1) The ciliary process was anteriorly directed, supporting the peripheral iris so that it was parallel to the trabecular meshwork.

2) The iris root had a steep rise from its point of insertion, followed by a downward angulation from the corneoscleral wall.

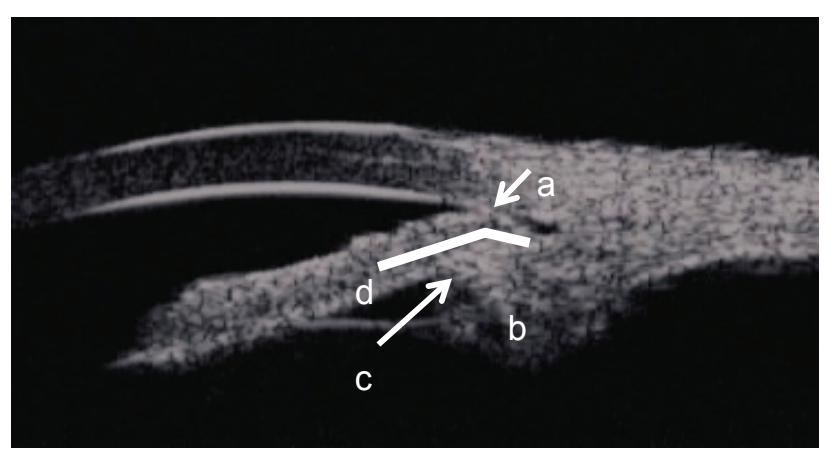

Figure I Ultrasound biomicroscopy image of a quadrant of a primary angle closure glaucoma eye with plateau iris.

Notes: Irido-angle contact (a), anteriorly directed ciliary process (b), absent ciliary sulcus (c), and iris angulation (d) are shown. 
3) Presence of a central flat iris plane.

4) An absent ciliary sulcus.

5) Irido-angle contact (above the level of the scleral spur) in the same quadrant.

At least two quadrants had to fulfill all the above criteria for an eye to be classified as having plateau iris (plateau iris group). No plateau iris group was defined as an eye to be classified as having less than one quadrant.

\section{Statistical analysis}

Statistical analysis was performed using SPSS version 15 for Windows (SPSS Inc., Chicago, IL, USA). Differences in mean values of parametric data among eyes of different subjects were examined using independent samples Student's $t$-test and Fisher's exact test. The anterior segment parameters of the plateau iris group, the no-plateau iris group, and the normal controls were compared by a one-way repeatedmeasures analysis of variance test. A $P$-value less than 0.05 was considered statistically significant.

\section{Results}

A total of 91 Japanese angle closure subjects (consisting of 58 PAC and 33 PACG subjects) and 68 normal controls were recruited. There were significant differences between the two groups for refractive errors $(P=0.03)$, gender $(P=0.006)$, ACD $(P<0.0000)$, LT $(P<0.0000)$, AL $(P<0.0000)$, LP $(P<0.0000)$, and RLP $(P=0.005)$. However, no difference was found for age $(P=0.38)$ (Table 1).

On quadrant-wise analysis, 18 of 91 eyes $(19.8 \%)$ were found to have plateau iris in one quadrant, ten of 91 eyes $(11.0 \%)$ in two quadrants, four of 91 eyes $(4.4 \%)$ in three quadrants, and two of 91 eyes $(2.2 \%)$ in all four quadrants. In 57 of 91 eyes $(62.6 \%)$, plateau iris was not found

Table I Comparison of biometric parameters between angle closure and NC groups

\begin{tabular}{llll}
\hline & PAC + PACG & NC & P \\
\hline Number of eyes & 91 & 68 & \\
Age (years) & $73.5 \pm 6.2$ & $72.6 \pm 7.3$ & 0.38 \\
Men/women & $12 / 79$ & $21 / 47$ & 0.006 \\
RE (D) & $0.85 \pm 1.84$ & $0.11 \pm 1.97$ & 0.03 \\
ACD $(\mathrm{mm})$ & $2.45 \pm 0.35$ & $3.14 \pm 0.35$ & $<0.0000$ \\
LT $(\mathrm{mm})$ & $4.99 \pm 0.48$ & $4.54 \pm 0.47$ & $<0.0000$ \\
AL $(\mathrm{mm})$ & $22.15 \pm 0.78$ & $23.30 \pm 0.8 \mathrm{I}$ & $<0.0000$ \\
LP $(\mathrm{mm})$ & $4.95 \pm 0.25$ & $5.38 \pm 0.45$ & $<0.0000$ \\
RLP & $0.224 \pm 0.013$ & $0.231 \pm 0.020$ & 0.005 \\
\hline
\end{tabular}

Note: Values are expressed as the mean \pm standard deviation. Abbreviations: PAC, primary angle closure; PACG, primary angle closure glaucoma; NC, normal control; RE, refractive error; ACD, anterior chamber depth; $L T$, lens thickness; AL, axial length; LP, lens position; RLP, relative lens position.
Table 2 Detection of eyes with plateau iris by ultrasound biomicroscopy

\begin{tabular}{llllll}
\hline Number of quadrants & 0 & $\geq 1$ & $\geq 2$ & $\geq 3$ & 4 \\
Number of eyes (\%) & $57(62.2)$ & $34(37.4)$ & $16(17.6)$ & $6(6.6)$ & $2(2.2)$ \\
\hline
\end{tabular}

in any quadrant (Table 2). Plateau iris was found in the superior quadrant in 16 eyes, inferior quadrant in eight eyes, nasal quadrant in 19 eyes, and temporal quadrant in 15 eyes (Table 3). Sixteen of 91 (17.6\%) eyes fulfilled all the criteria for plateau iris on UBM. There were no cases of plateau iris in the controls.

To determine the effect of plateau iris on the ocular biometrics, we divided the angle closure group into two groups (plateau iris group and no-plateau iris group) and compared them (Table 4). No significant differences were noted for age $(P=0.60)$, gender $(P=0.93)$, refractive error $(P=0.48)$, ACD $(P=0.41)$, LT $(P=0.15)$, AL $(P=0.75)$, LP $(P=0.81)$, and RLP $(P=0.98)$. (Table 4). The ACDs (mean \pm standard deviation) of the plateau iris group, no-plateau iris group, and normal controls were $2.52 \pm 0.43 \mathrm{~mm}, 2.43 \pm 0.34 \mathrm{~mm}$, and $3.14 \pm 0.34 \mathrm{~mm}$, respectively (analysis of variance; $\left.P=8.3 \times 10^{-4}\right)$. The ACDs of the plateau iris group and noplateau iris group were significantly shallower than those of normal controls, respectively $(P=0.01)$. There was no statistically significant difference in the prevalence of plateau iris between PAC and PACG $(P=0.91)$ (Table 5).

\section{Discussion}

Mechanisms other than pupil block were suggested to be involved in the pathogenesis of angle closure glaucoma in Japanese patients. ${ }^{14}$ In this study, using UBM, plateau iris was observed in $17.6 \%$ of the Japanese patients with PAC or PACG who had undergone LPI. The frequency of plateau iris in Asian patients with PACG has been reported to be $30 \%$ in Singapore, ${ }^{7,8} 36.9 \%$ in Thailand, ${ }^{7}$ and $30 \%$ in India, ${ }^{15}$ being about two times higher than in Japan. The prevalence of PACG in Asians has been reported to be $1.0 \%$ in Singaporeans, ${ }^{5} 1.58 \%$ in Indians, ${ }^{16}$ and $0.9 \%$ in Thailand, ${ }^{17}$ being about two times higher than the $0.6 \%$ in Japanese patients. ${ }^{18}$ This correlation between the prevalence rates of

Table 3 Detection of plateau iris in each quadrant by ultrasound biomicroscopy

\begin{tabular}{lllll}
\hline & $\begin{array}{l}\text { Superior } \\
\text { quadrant }\end{array}$ & $\begin{array}{l}\text { Inferior } \\
\text { quadrant }\end{array}$ & $\begin{array}{l}\text { Temporal } \\
\text { quadrant }\end{array}$ & $\begin{array}{l}\text { Nasal } \\
\text { quadrant }\end{array}$ \\
\hline $\begin{array}{l}\text { Number of plateau } \\
\text { iris eyes (\%) }\end{array}$ & $16(17.6)$ & $8(8.8)$ & $15(16.5)$ & $19(20.9)$ \\
\hline
\end{tabular}


Table 4 Comparison of biometric parameters between plateau iris group and no-plateau iris group

\begin{tabular}{llll}
\hline & $\begin{array}{l}\text { Plateau iris } \\
\text { group }\end{array}$ & $\begin{array}{l}\text { No-plateau iris } \\
\text { group }\end{array}$ & $\boldsymbol{P}$ \\
\hline Number of eyes & 16 & 75 & \\
Age (years) & $72.6 \pm 5.5$ & $73.7 \pm 6.3$ & 0.61 \\
Men/women & $2 / 14$ & $10 / 65$ & 0.93 \\
RE & $1.15 \pm 1.34$ & $0.79 \pm 1.93$ & 0.48 \\
ACD $(\mathrm{mm})$ & $2.52 \pm 0.43$ & $2.43 \pm 0.34$ & 0.41 \\
LT $(\mathrm{mm})$ & $4.83 \pm 0.51$ & $5.03 \pm 0.48$ & 0.15 \\
AL $(\mathrm{mm})$ & $22.09 \pm 0.60$ & $22.16 \pm 0.82$ & 0.75 \\
LP $(\mathrm{mm})$ & $4.93 \pm 0.25$ & $4.95 \pm 0.25$ & 0.81 \\
RLP & $0.224 \pm 0.014$ & $0.234 \pm 0.013$ & 0.98 \\
\hline
\end{tabular}

Notes: Plateau iris group $=$ having plateau iris in $\geq 2$ quadrants; no-plateau iris group $=$ having plateau iris in $\leq \mathrm{I}$ quadrant. Values are expressed as the mean \pm standard deviation.

Abbreviations: RE, refractive errors; ACD, anterior chamber depth; $L T$, lens thickness; AL, axial length; LP, lens position; RLP, relative lens position.

plateau iris and PACG is of interest, and plateau iris is considered to be an important factor in angle closure glaucoma after relieving pupil block in Asians.

Conventionally, plateau iris has been diagnosed on the basis of angle findings in patients who have undergone laser iridotomy as narrowing of the peripheral angle in those with a relatively deep central anterior chamber. However, Kumar et al reported that plateau iris was observed by UBM in about $30 \%$ of patients who are PACS or have PACG, and the ACD was shallow in these patients. ${ }^{7,8,15}$ In this study, involving Japanese patients with PAC or PACG, plateau iris was noted in patients with an ACD significantly shallower than that in the normal controls. Mandell et al reported that a plateau iris group showed an ACD significantly shallower than that of the normal control group and the pupil block group. ${ }^{13}$ They suggested forward shift of the lens due to anterior displacement of the ciliary body, causing shallowing of the ACD, as a reason for these findings in the plateau iris group. However, an anterior LP is also a condition that leads to pupil block, and it is likely that these conditions frequently coexist. A shallow ACD, thick lens, and short AL have been considered risk factors of angle closure glaucoma. ${ }^{19-21}$ No significant difference was observed in these parameters between the

Table 5 The prevalence of plateau iris between PAC and PACG

\begin{tabular}{llll}
\hline & PAC & PACG & P \\
\hline Plateau iris group (n=eye) & 10 & 6 & \\
No-plateau iris group (n=eye) & 48 & 27 & 0.91 \\
\hline
\end{tabular}

Notes: Plateau iris group is defined as having plateau iris in $\geq 2$ quadrants; noplateau iris group is defined as having plateau iris in $\leq$ I quadrant.

Abbreviations: PAC, primary angle closure; PACG, primary angle closure glaucoma. plateau iris group and no-plateau iris group in this study. Our results contradict the general view that the ACD is normal or deep in patients with plateau iris and the report of Mandell et al. ${ }^{13}$ According to Mochizuki et $\mathrm{al}^{22}$ plateau iris was noted frequently (34.6\%) in Japanese patients with chronic angle closure glaucoma. Surprisingly, it was also noted in $19.2 \%$ of those with open angle glaucoma. Yeung et $\mathrm{al}^{23}$ and Sakata et $\mathrm{al}^{24}$ reported that abnormal positioning of the ciliary body was found in normal controls. Thus, eyes with open angle might have also a higher rate of plateau iris than expected in the Japanese patients. This is the reason why there was no statistical difference between the plateau iris group and no-plateau iris group.

Progression from PAC to PACG was reported to occur in approximately $20 \%$ of patients who underwent LPI. ${ }^{6}$ Therefore, PAC does not necessarily progress to PACG, and $\mathrm{PAC}$ at high risk for angle closure is considered more likely to develop to PACG. However, no significant difference was noted in the frequency of plateau iris between the PAC and PACG groups in this study. A recent study using anterior segment optical coherence tomography showed that the progression of angle closure is affected by the iris thickness, area, and volume. ${ }^{25,26}$ Embryologically, the ciliary body and iris root in week 24 of intrauterine life and mature as different organs. ${ }^{27}$ Therefore, abnormalities occurring in this period may cause morphological abnormalities in both structures. The thickness of the iris root affects the angle width. Therefore, a thicker peripheral iris is likely to contribute to angle closure as the peripheral iris would be in closer proximity to the angle. This may be especially important in eyes with shallow and crowded anterior chambers. Plateau iris and a thick peripheral iris are likely to co-occur, further increasing the risk of angle closure. Continued evaluation involving a larger number of patients is necessary.

This study has several limitations. First, we did not look at the association of the lens parameters with cataract status. Since the ACD has been reported to shallow with cataract progression, ${ }^{28,29}$ it is important to exclude the effect of cataract when comparing the ACD. However, in our data, there were no significant difference of LT and ACD between the plateau iris group and no-plateau iris group. From this point, we think that the cataract status might have been equal in these two groups. Second, factors such as accommodation and lighting, which may induce changes in lens parameters, were not evaluated. Third, this study was carried out at two separate facilities, and UBM was performed by different investigators. This may have resulted in bias in measurements. 
Fourth, UBM scan and grading of the images were performed by the same investigator (TM), so the judgments may have been biased.

\section{Conclusion}

Plateau iris was observed by UBM in approximately $20 \%$ of the Japanese patients who had previously undergone LPI for PAC or PACG and highlight the significance of non-pupil block mechanisms for angle closure in the Japanese angle closure patients. However, no morphological difference was noted in the anterior segment of the eye between those with and without plateau iris.

\section{Disclosure}

The authors report no conflicts of interest in this work.

\section{References}

1. Quigley HA, Broman AT. The number of people with glaucoma worldwide in 2010 and 2020. Br J Ophthalmol. 2006;90:262-267.

2. Foster PJ, Johnson GL. Glaucoma in China: how big is the problem? Br J Ophthalmol. 2001;85:1277-1282.

3. Bengtsson B. The prevalence of glaucoma. Br J Ophthalmol. 1981;65: $46-49$.

4. He M, Foster PJ, Ge J, et al. Prevalence and clinical characteristics of glaucoma in adult Chinese: a population-based study in Liwan District, Guangzhou. Invest Ophthalmol Vis Sci. 2006;47:2782-2788.

5. Foster PJ, Oen FTS, Machin D, et al. The prevalence of glaucoma in Chinese residents of Singapore: a cross-sectional population survey of the Tanjong Pagar district. Arch Ophthalmol. 2000;118:1105-1111.

6. Alsagoff Z, Aung T, Ang LP, Chew PT. Long-term clinical course of primary angle-closure glaucoma in an Asian population. Ophthalmology. 2000;107:2300-2304

7. Kumar RS, Tantisevi V, Wong MH, et al. Plateau iris in Asian subjects with primary angle closure glaucoma. Arch Ophthalmol. 2009;127: 1269-1272.

8. Kumar RS, Baskaran M, Chew PT, et al. Prevalence of plateau iris in primary angle closure suspects an ultrasound biomicroscopy study. Ophthalmology. 2008;115:430-434.

9. Bhargava SK, Leighton DA, Phillips CI. Early angle-closure glaucoma. Distribution of iridotrabecular contact and response to pilocarpine. Arch Ophthalmol. 1973;89:369-372.

10. Kunimatsu S, Tomidokoro A, Mishima K, et al. Prevalence of appositional angle closure determined by ultrasonic biomicroscopy in eyes with shallow anterior chambers. Ophthalmology. 2005;112:407-412.

11. Kong X, Foster PJ, Huang Q, et al. Appositional closure identified by ultrasound biomicroscopy in population-based primary angle-closure glaucoma suspects: the Liwan eye study. Invest Ophthalmol Vis Sci. 2011;52:3970-3975.
12. He M, Friedman DS, Ge J, et al. Laser peripheral iridotomy in eyes with narrow drainage angles: ultrasound biomicroscopy outcomes. The Liwan Eye Study. Ophthalmology. 2007;114:1513-1519.

13. Mandell MA, Pavlin CJ, Weisbrod DJ, Simpson ER. Anterior chamber depth in plateau iris syndrome and pupillary block as measured by ultrasound biomicroscopy. Am J Ophthalmol. 2003;136:900-903.

14. Ozaki M, Nongpiur ME, Aung T, He M, Mizoguchi T. Increased lens vault as a risk factor for angle closure: confirmation in a Japanese population. Graefes Arch Clin Exp Ophthalmol. 2012;250:1863-1868.

15. Kumar G, Bali SJ, Panda A, Sobti A, Dada T. Prevalence of plateau iris configuration in primary angle closure glaucoma using ultrasound biomicroscopy in the Indian population. Indian J Ophthalmol. 2012; $60: 175-178$

16. Vijaya L, George R, Arvind H, et al. Prevalence of angle-closure disease in a rural southern Indian population. Arch Ophthalmol. 2006; 124:403-409.

17. Bourne RR, Sukudom P, Foster PJ, et al. Prevalence of glaucoma in Thailand: a population based survey in Rom Klao District, Bangkok Br J Ophthalmol. 2003;87:1069-1074.

18. Yamamoto T, Iwase A, Araie M, et al; Tajimi Study Group, Japan Glaucoma Society. The Tajimi Study report 2: prevalence of primary angle closure and secondary glaucoma in a Japanese population. Ophthalmology. 2005;112:1661-1669.

19. Aung T, Nolan WP, Machin D, et al. Anterior chamber depth and the risk of primary angle closure in 2 East Asian populations. Arch Ophthalmol. 2005; 123:527-532.

20. Lavanya R, Wong TY, Friedman DS, et al. Determinants of angle closure in older Singaporeans. Arch Ophthalmol. 2008;126:686-691.

21. Wojciechowski R, Congdon N, Anninger W, Teo Broman A. Age, gender, biometry, refractive error, and the anterior chamber angle among Alaskan Eskimos. Ophthalmology. 2003;110:365-375.

22. Mochizuki H, Takenaka J, Sugimoto Y, Takamatsu M, Kiuchi Y. Comparison of the prevalence of plateau iris configurations between angle-closure glaucoma and open-angle glaucoma using ultrasound biomicroscopy. J Glaucoma. 2011;20:315-318.

23. Yeung BY, Ng PW, Chiu TY, et al. Prevalence and mechanism of appositional angle closure in acute primary angle closure after iridotomy. Clin Experiment Ophthalmol. 2005;33:478-482.

24. Sakata LM, Sakata K, Susanna R Jr, et al. Long ciliary processes with no ciliary sulcus and appositional angle closure assessed by ultrasound biomicroscopy. J Glaucoma. 2006;15:371-379.

25. Wang B, Sakata LM, Friedman DS, et al. Quantitative iris parameters and association with narrow angles. Ophthalmology. 2010;117:11-17.

26. Wang BS, Narayanaswamy A, Amerasinghe N, et al. Increased iris thickness and association with primary angle closure glaucoma. $\mathrm{Br}$ J Ophthalmol. 2011;95:46-50.

27. Remé C, d'Epinay SL. Periods of development of the normal human chamber angle. Doc Ophthalmol. 1981;51:241-268

28. Okabe I, Taniguchi T, Yamamoto T, Kitazawa Y. Age-related changes of the anterior chamber width. J Glaucoma. 1992;1:100-107.

29. Fontana ST, Brubaker RF. Volume and depth of the anterior chamber in the normal aging human eye. Arch Ophthalmol. 1980;98 1803-1808.
Clinical Ophthalmology

\section{Publish your work in this journal}

Clinical Ophthalmology is an international, peer-reviewed journa covering all subspecialties within ophthalmology. Key topics include: Optometry; Visual science; Pharmacology and drug therapy in eye diseases; Basic Sciences; Primary and Secondary eye care; Patient Safety and Quality of Care Improvements. This journal is indexed on Submit your manuscript here: http://www.dovepress.com/clinical-ophthalmology-journal

\section{Dovepress}

PubMed Central and CAS, and is the official journal of The Society of Clinical Ophthalmology (SCO). The manuscript management system is completely online and includes a very quick and fair peer-review system, which is all easy to use. Visit http://www.dovepress.com/ testimonials.php to read real quotes from published authors. 